\title{
Uneven accessibility to biomarker test for lung cancer
}

$\mathrm{T}$ he treatment of lung cancer has advanced significantly over the last decade, with the identification of genetic markers that distinguish patients who are much more likely to respond positively to specific drugs. Although good news for oncologists eager to find the best therapy, treatment success depends on how well patients are screened for their suitability. And Canada's patchwork system of genetic testing for lung cancer makes that problematic.

"The provincial governments by and large have been very slow to move on this issue of molecular testing," says Dr. Peter Ellis, an associate professor in the Department of Oncology at McMaster University in Hamilton, Ontario. "If we're going to be able to provide appropriate care to these patients, we need to have systems in place for testing. For a government to approve a drug without providing a mechanism to test, to see who that drug's appropriate for, is not progressive."

The drug that Ellis is referring to is IRESSA (gefitinib), an oral medication that interferes with cellular signalling pathways responsible for the growth of tumours and the spread of many cancers. Gefitinib is most effective in patients with a specific genetic biomarker: a mutation in a gene called the epidermal growth factor receptor (EGFR). About $10 \%$ of patients in North America have this mutation, compared with about a third in East Asia; a study of ethnically mixed Canadian patients who have been tested showed that around $18 \%$ had the EGFR mutation.

In 2002, Japan became the first country to approve gefitinib for use in advanced cases of lung cancer. Health Canada approved this same use in 2010, when the drug's manufacturer, AstraZeneca, sponsored the country's first EGFR mutation testing program.

Ellis was principal investigator in an assessment of the testing program's impact on patient care. There were over 2100 requests for EGFR mutation testing during the first 10 months and about 1770 of those were eligible. Among those tested, 302 patients, $17.1 \%$ of the total, were prescribed gefitinib for lung cancer.

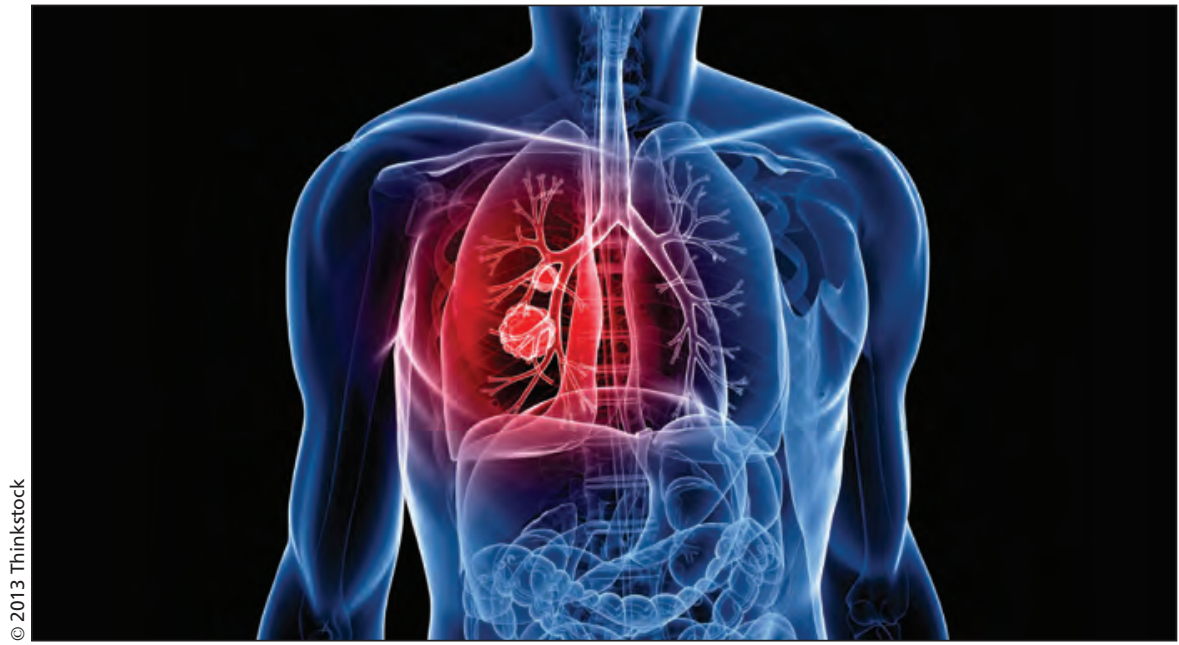

According to a new study, about $18 \%$ of Canadian patients with lung cancer had a mutation in a gene called the epidermal growth factor receptor, which responds to the drug gefitinib.

These findings, to be published in the September issue of the International Association for the Study of Lung Cancer publication, the Journal of Thoracic Oncology, revealed a rapid uptake in EGFR mutation testing during the 12 months when it was subsidized by AstraZeneca. The program received 200-250 test requests a month. But once the subsidy ended, oncologists were faced with a cost of about $\$ 400$ per patient and the number of requests fell to 50-100 per month.

Only BC and Alberta (which serves all the Prairies) support access to testing for the EGFR mutation and funding for gefitinib. Atlantic Canada has no such facilities, although tissue samples can be forwarded to Montréal, Quebec. In Ontario and Quebec, where only $10 \%-15 \%$ of eligible lung cancer patients may be tested, provincial ministries of health are just beginning to fund this procedure.

"As an oncologist, we like to think that a patient in Newfoundland or Nova Scotia gets treated the same as someone in Alberta or British Columbia," says Barbara Melosky, an oncologist with the BC Cancer Agency and the University of British Columbia in Vancouver.

EGFR mutation testing is now the standard of care, she says, and it can extend the survival of stage-4 patients from months to years. "It really has changed that patient's life to find the mutation and apply the proper inhibitor for that mutation," she said.

"If this was breast cancer, there would be a public outcry," she adds. "We know that with breast cancer, if you have estrogen-positive breast cancer, it's appropriate to give drugs like tamoxifen or aromatase inhibitors. If you're estrogen-receptor negative, you don't get those drugs. If you're HER2 positive, you should be getting herceptin; if you're HER2 negative, you shouldn't be getting herceptin."

By publishing the results of the AstraZeneca-funded EGFR mutation testing trial, Ellis and his colleagues intend to remind health care authorities that other patients with cancer can also benefit from support for this kind of personalized medicine.

Melosky says the cost of testing will decrease as testing becomes more widely implemented and less specialized so that tumour samples can be simultaneously examined for a range of genetic biomarkers for identifying the most efficient treatment.

"That's the future, but it's not arrived yet," she acknowledges. "People talked about targeted therapy, and I never believed it would happen, and now it really is all about that. It's time that governments stepped up to the plate and we try to make this a reality not just for one province, but for all." - Tim Lougheed, Ottawa, Ont.

CMAJ 2013. DOI:10.1503/cmaj.109-4577 